\section{P057 \\ ECOSAPENTANOIC ACID (EPA) DOES NOT AFFECT CELL KINETICS IN PERIPHERAL LYMPHOCYTES FROM PATIENTS WITH CROHN'S DISESASE (CD) ACCORDING TO IL6-174G/C POLYMORPHISM}

M.D. Brito ${ }^{1}$, P. Ferreira ${ }^{1}$, C. Guerreiro ${ }^{2}$, J. Vacas ${ }^{1}$, L. Tavares ${ }^{3}$, P. Santos ${ }^{3}$, A. Pinto ${ }^{4}$, M. Cravo ${ }^{5} .{ }^{1}$ Genetics, ${ }^{2}$ Dietetics, Escola Superior de Tecnologia da Saude de Lisboa, ${ }^{3}$ Gastroenterology, Hospital de Santa Maria, ${ }^{4}$ Citology, ${ }^{5}$ Gastroenterology, Instituto Português de Oncologia, Lisbon, Portugal

Rationale: Omega 3 fatty acids have been shown to be of potential benefit in patients with $C D$. The aim of the present study was to evaluate whether EPA can modulate the inflammatory response according to different genotypes of IL6G174G/C polymorphism.

Methods: Peripheral blood cells were collected from CD patients with different genotypes for IL6-174G/C (GG, $n=16, G C, n=8, C C, n=7$ ), and lymphocytes were established in culture media. Replicates with the addition of EPA $(25 \mu \mathrm{M})$ were analysed in a period of $24 \mathrm{~h}, 48 \mathrm{~h}$ and 72h. Expression of IL6 e a PGE2 was assessed by ELISA. Apoptosis and cellular proliferation was determined by flow cytometry.

Results: We observed a significant difference in IL6 production between the 3 genotypes with or without addition of EPA (GG, $1392 \mathrm{pg} / \mathrm{ml}$, GC, 1256, CC 999, $p=0.01)$. No significant differences were observed in IL6 production with EPA addition, however a slight decrease in IL6 production was detected for CC genotype (24h, $1051 \mathrm{pg} / \mathrm{ml}, 48 \mathrm{~h}, 926,72 \mathrm{~h}, 916, \mathrm{p}=0.49)$. In what concerns PGE2 no significant differences were observed between genotypes or with the addition of EPA ( $p>0.05)$. Once again a slight PGE2 increase was observed for CC genotype (GG, $11.5 \mathrm{pg} / \mathrm{ml}$, GC, 10.71, CC 12.15, $p=0.562$ ). Significant lower proliferation index (GG, $31.7 \%, G C, 27.6$, CC 17.7, $p=0.003$ ) and significantly higher apoptosis rate was observed for IL6-174CC genotype (GG, 20.3\%, GC, 22.7, CC 29.7, p=0.004). However with such small number of individual any significant effect could be disclosed

Conclusion: This study shows the complex pathway of inflammatory process in $C D$, and the possible differential response of genotypes (namely IL6 174 CC) to nutrients (EPA). Moreover significant differences in IL6 production, proliferation index and apoptosis was observed for IL6 174 CC genotype

Disclosure of Interest: None declared

\section{P058}

TNF-ALPHA-308 POLYMORPHISM AND AGE INFLUENCE THE EFFECTS OF FISH OIL ON MONOCYTE CYTOKINE PRODUCTION AND PLASMA LIPIDS IN HEALTHY MEN

R. Grimble ${ }^{1}$, J. Madden ${ }^{1}$, A. Brunner ${ }^{1}$, J. Carrero ${ }^{1}$, P. Calder ${ }^{1} .{ }^{1}$ Institute of Human Nutrition, Southampton University Medical School, Southampton, United Kingdom

Rationale: Fish oil is reputed to reduce cytokine production by leukocytes, and lower fasting TAG and raise cholesterol concentrations in plasma in healthy men. The effects vary from study to study. We investigated the effects of age and a pro-inflammatory genotype on the variability of these responses in men given $6 \mathrm{~g} / \mathrm{d}$ MaxEPA fish oil for 12 weeks.

Methods: Subjects were divided according to their age (under 60 year and 60 and older) and whether they possessed an A allele for the TNF- $\alpha-308$ polymorphism. Results: See the table. Number of subjects in each age group $(\mathrm{n})$

\begin{tabular}{|c|c|c|c|c|}
\hline \multirow{2}{*}{$\begin{array}{l}\text { TNF- } \alpha-308 \\
\text { A allele }\end{array}$} & \multicolumn{2}{|l|}{$<60$ years } & \multicolumn{2}{|l|}{$\geqslant 60$ years } \\
\hline & $\begin{array}{l}\text { Pre- } \\
\text { supplement }\end{array}$ & Change & $\begin{array}{l}\text { Pre- } \\
\text { supplement }\end{array}$ & Change \\
\hline \multicolumn{5}{|c|}{ TNF $-\alpha$ production $(\mathrm{ng} / \mathrm{ml})$} \\
\hline Present & $47.2 \pm 43.7$ & $20.2 \pm 85.9^{a}$ & $125.0 \pm 182.8^{*}$ & $-83.4 \pm 181.2^{\mathrm{a}}$ \\
\hline Absent & $41.1 \pm 38.8$ & $0.6 \pm 31.8^{\mathrm{a}}$ & $45.0 \pm 46.7^{*}$ & $56.2 \pm 154.5^{\mathrm{b}}$ \\
\hline \multicolumn{5}{|c|}{ Triacylglycerol (mmol/l) } \\
\hline Present & $1.66 \pm 1.02$ & $-0.14 \pm 0.69$ & $1.25 \pm 0.74$ & $-0.25 \pm 0.32^{* *}$ \\
\hline Absent & $1.48 \pm 0.75$ & $-0.02 \pm 0.69$ & $1.40 \pm 0.59$ & $-0.15 \pm 0.23^{* *}$ \\
\hline \multicolumn{5}{|c|}{ LDL cholesterol $(\mathrm{mmol} / \mathrm{l})$} \\
\hline Present & $4.77 \pm 0.98$ & $0.15 \pm 0.57$ & $3.82 \pm 0.63$ & $0.29 \pm 0.46^{*}$ \\
\hline Absent & $4.47 \pm 0.94$ & $0.06 \pm 0.69$ & $4.22 \pm 0.75$ & $0.01 \pm 0.45$ \\
\hline
\end{tabular}

${ }^{\mathrm{a}, \mathrm{b}}$ Changes in cytokine production after fish oil supplementation bearing the same postscripts are significantly different, $p=0.008$. *Initial value of TNF- $\alpha$ production between subjects with and without the A allele for the TNF- $\alpha-308$ SNP different by Mann-Whitney Test $p=0.079$. Significant change in fasting plasma lipid concentrations by paired t-test ${ }^{*} p<0.05$; or by Wilcoxon signed ranks test ${ }^{* *} p<0.05$

Conclusion: Possession of the TNF- $\alpha-308$ A allele and an age of 60 or over make it more likely that fish oil will exert its reputed effects on cytokine production and lipid metabolism than absence of the allele and a younger age in men. The effects may thus occur when inflammatory stress is elevated.

Disclosure of Interest: None declared

P059

GENE EXPRESSION IN MICROGRAVITY CULTURED OSTEOBLASTS APROPOS NUTRITIONAL INTERVENTION

A. Sundaresan ${ }^{1} .{ }^{1}$ Biology, Texas Southern University, Houston, USA

Rationale: Increased bone resorption and reduced bone formation are two major risk factors in ageing, microgravity and other stressful milieu. Nutritional compounds via specific mechanisms might reverse these risks by different magnitudes and mechanisms.

Methods: Human osteoblasts cultured in microgravity as a stressor over a period of three weeks were nourished with curcumin, specific plant extracts and nucleotides to observe their effects on the growth, and mineralization abilities of these cells. Corresponding in vitro corelates such as gene expression pertaining to the particular compounds by immunohistochemistry and real time PCR. Results: Curcumin nourishment revealed increased expression of osteocalcin a late differentiation marker, in microgravity cultured osteoblsts compared to controls while nucleotides revealed similar expression of osteocalcin but elevated levels of TGF- $\beta$. Plant extracts showed reduction in antiapoptotic genes such as bax. Overall the growth of osteoblasts was enhanced more by curcumin and nucleotides followed by plant extracts (curcumin, nucleotides, plant extracts). Mineralization was promoted more by nucleotides. 